\title{
Synthesis and characterization of silica prepared by thermal method
}

\author{
Feza Geyikçi
}

\begin{abstract}
Silica is a basic raw material that is widely used in many industrially important products such as electronics, ceramic, pharmaceutics, detergents, adhesives and polymer materials. The sources such as rice husk, groundnut shell, almond shell, bamboo leaves and sugarcane bagasse are considered as a waste material. These waste materials in large quantities can create a serious environmental problem. At harvesting time, these waste materials are burnt to release nutrients for the next growing season and to get rid of the huge quantity of it. During burning, carbon, oxygen and hydrogen elements which are present in these waste materials are converted into flammable gases such as carbon monoxide, hydrogen, methane and ash. Combustion of the almond shell produces almond shell ash, which consists of mainly silica and carbon. In this study, almond shells are subjected to moisture removal in a hot plate and sintered $450{ }^{\circ} \mathrm{C}, 700{ }^{\circ} \mathrm{C}$ and $900{ }^{\circ} \mathrm{C}$ by thermal methods for 10,8 and $7 \mathrm{~h}$, respectively. The sintered powder was treated with $1 \mathrm{M} \mathrm{NaOH}$ to form sodium silicate. In a systematic study, results demonstrated that almond shell produced amorphous silica $\left(\mathrm{SiO}_{2}\right)$. The prepared silica was characterized by FT-IR, XRD and SEM analysis. FT-IR results showed a good peak correlation between the commercial silica and burnt almond shell residue.
\end{abstract}

\section{Keywords—silica, almond shell, thermal treatment}

\section{Introduction (Heading 1)}

Silicon is the basis of several industries. The construction industries rely on on sand and cement, which is basically a calcium silicate. Glass manufacture is based on sand. Sand is also reduced to silicon as a raw material for the steel, chemical and electronics industries by heating it with coke (carbon) in an electric furnace with carbon electrodes, operating at $2000{ }^{0} \mathrm{C}$. Provided the silica is in excess, the product is silicon, in the amorphous form; most of this goes into making ferrosilicon for steel.

Considering silicon's abundance, it is somewhat surprising that silicon aroused little curiosity among early chemists, even thought it was clearly important to plants, and had long been known that the ash from straw burning could be turned into glass. The earth's crust is composed primarily of silicate minerals, which explains why silicon is second only to oxygen in its abundance. The great variety of silicate rocs comes about as a result of the chemical versatility of the silicate ion, $\left[\mathrm{SiO}_{4}\right]^{4-}$, which consists of a silicon atom attached to four atoms.

\section{Feza Geyikçi}

Ondokuz Mayıs University, Chemical Engineering Depart Turkey
Silicon, in the form of silica, was used by humans to make one of their first types of tool: sharp flints. The ancient civilizations used other forms of silica such as rock crystal and knew how to turn sand into glass, developing sophisticated technology for its production, colouring and shaping [1]. Silica is a polymer of silicic acid consisting of inter-linked $\mathrm{SiO}_{4}$ units in tetrahedral fashion with general formula $\mathrm{SiO}_{2}$. In nature it exists as sand, glass, quartz etc. Naturally occurring silica is crystalline whereas synthetically obtained silica is amorphous in nature. It is widely used in several industries. Because of its particles diameter, ultrafine silica powders have many technological applications, such as tixotropic agents, thermal insulators, composite filler, etc. [2]. The conventional process of extracting silica in pure form from the natural quartz sources involves a high cost of production [3]. Silica is the second most abundant element in the earth surface, which accounts for approximately $32 \%$ of the total weight of it. As a consequence, plants rooting in soil always contain some silicon in their tissues [3-4]. The nature of herbal amorphous silica (plants with high content of silica), makes it extractable at lower temperature, and hence provides a low energy method as an alternative to the current high energy methods of silica extraction. Some of the herbal silica source is either an agricultural waste or industrial byproduct. For example, the annual yield of rice husks and straws was about 127 million tons in 2008 [4].

Silica used to in chemical applications are synthesized either from silicate solution or silane reagents. Sol-gel technique is the most common method for silica synthesis. Addition of acid or base catalyses the process and addition of an electrolyte or change in $\mathrm{pH}$ of sol influences the condensation process. Concentrated ammonia solution in ethanol and water was also used for the hydrolysis and condensation of tetraethoxy silane to prepare monodispersed silica with low surface area by using SFB methods [5]. Colloidal silica can be obtained by peptization of a hydro wet gel prepared from a mixture of sodium silicate solution with acid and water. The silica sources are rice husk, groundnut shell, bamboo leaves and sugarcane bagasse. They are considered as a waste material. At harvesting time, these waste materials are burnt to release nutrients for the next growing season and to get rid of the huge quantity of it [6-7]. During burning, carbon, oxygen, and hydrogen elements which are present in these waste materials are converted into flammable gases such as carbon monoxide, hydrogen, methane and ash. This ash is rich in silica and carbon and it has no exploitation yet. Many investigations have shown that pure amorphous silica can be prepared from cheap agricultural wastes [4].

The main objective of this study is to develop an efficient route to extract amorphous silica from almond 
shell. Silica is produced by the thermal method. The obtained solution was characterized by FT-IR, XRD and SEM analysis to confirm the functional group and purity of silica.

\section{Experimental}

\section{A. Materials}

For silica production, in order to lower the cost of material, natural materials are being used. Almond bark is used that is one of the natural materials that have limited research area. For this purpose, our country has been supplying the almonds for analysis, which are grown in Datça region by separating their shells. For the extraction, $\mathrm{NaOH}$ was obtained from Sigma Aldrich.

\section{B. Synthesis of Silica}

First, Almond Shell was washed thoroughly with water to remove the soluble particles and dust or any other contaminants. Second, it was dried in air oven at about 80 ${ }^{0} \mathrm{C}$ for $48 \mathrm{~h}$. The particle size of almond shell was distributed within a range of $2-4 \mathrm{~mm}$. The almond shell of $5 \mathrm{~g}$ was placed in the furnace at $450{ }^{\mathrm{O}} \mathrm{C}, 700{ }^{\mathrm{O}} \mathrm{C}$ and $900{ }^{8} \mathrm{C}$ by thermal methods for 10,8 and $7 \mathrm{~h}$, respectively.

After the different temperature degrees and for different times, it was sintered in order to remove the volatile gases and converted to respective ash powders. Silica nanoparticles have been prepared through dissolution and extraction process. The solution of silica was carried out using an alkali leaching process using $1 \mathrm{M} \mathrm{NaOH}$ to partially dissolve carbonaceous materials.

The sintered powder (ash) was treated with $1 \mathrm{M} \mathrm{NaOH}$ to form sodium silicate.

\section{Characterization}

The chemical bond in the prepared sodium silicate solutions was studied by using Fourier infrared spectroscopy. The study was carried out in the wave number of $600-4000 \mathrm{~cm}^{-1}$. The XRD measurement was taken at the step size of $0.02 \mathrm{deg} / \mathrm{min}$ by using $\mathrm{Cu} \mathrm{K} \alpha$ and $\mathrm{Ni}$ filtered radiation. The surface morphology was studied by scanning electron microscobe (SEM).

\section{Results and Discussion}

The almond shells are converted to ash by sintering at $450{ }^{\circ} \mathrm{C}, 700{ }^{\circ} \mathrm{C}$ and $900{ }^{\circ} \mathrm{C}$ which is taken for the alkali treatment. It was calculated for efficiency of ash amount (Table I). According to results, maximum efficiency was observed at $700{ }^{\circ} \mathrm{C}$.
TABLE I.

\begin{tabular}{|l|c|}
\hline \multirow{2}{*}{ Temperature } & Efficiency of Ash Amount \\
\cline { 2 - 2 } & $(\%)$ \\
\hline $450{ }^{\circ} \mathrm{C}$ & 27.50 \\
\hline $700{ }^{\circ} \mathrm{C}$ & 52.20 \\
\hline $900{ }^{\circ} \mathrm{C}$ & 25.80 \\
\hline
\end{tabular}

FT-IR spectrum results of the materials generated from almond shell burning $700{ }^{\circ} \mathrm{C}$ are shown in Fig. 1. A large peak was observed between 1500 and $3500 \mathrm{~cm}-1$ corresponding to the stretching vibrations of the surface silanols $(\mathrm{SiOH})$ groups perturbed by hydrogen bounds either intramoleculary or with adsorbed water. The intense bands at $800 \mathrm{~cm}^{-1}$ and $650 \mathrm{~cm}^{-1}$ are due to symmetric stretching and bending vibrations of Si-O-Si. Bock and Su [xx] have recorded the IR spectrum of fused silica and compared it with the results of vibrational calculations. They found that the bands such as 465, 800, 950, 1100 and $1190 \mathrm{~cm}^{-1}$ are related to fused silica. Generally, these IR bands are appeared in various forms of silica such as quartz, cristobalite and tridymite respectively. Also, the absorption bans at $1400 \mathrm{~cm}^{-1}$ and $873 \mathrm{~cm}^{-1}$ are obserbed in all the FT-IR spectra of alkali treated samples, which confirms the formation of sodium silicate [5].

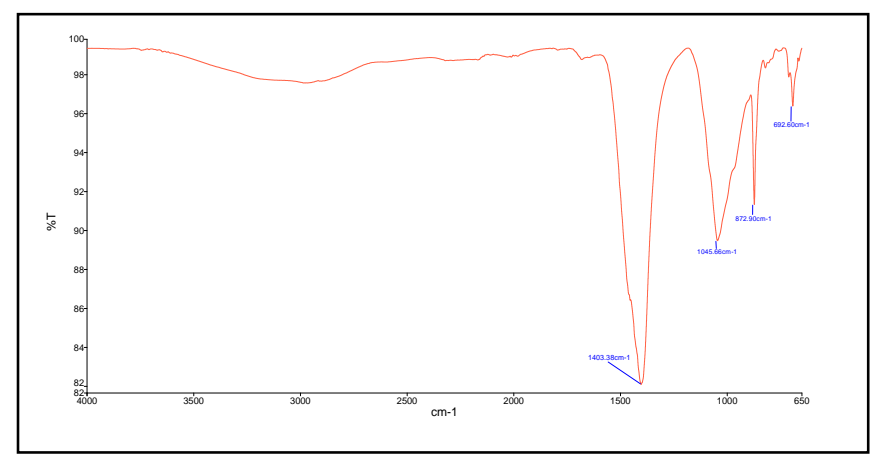

Figure 1. FT-IR spectrum of the almond shell ash $\left(700{ }^{\circ} \mathrm{C}\right)$

The alkali treated almond shell ash have shown a peak at $1403 \mathrm{~cm}^{-1}$, which is due to the formation of Si-O-Na bond, whereas the sample of ash have shown an additional peak at $873 \mathrm{~cm}^{-1}$ that indicated the formation of Si-O- Al phase.

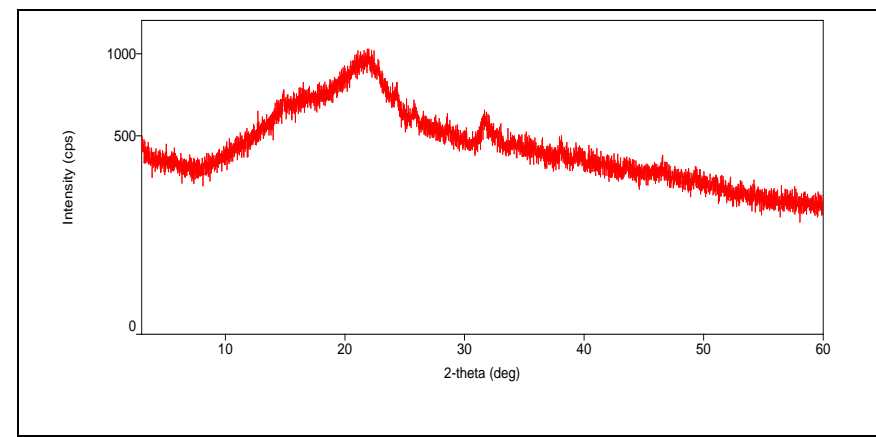

Figure 2. XRD spectrum for the almond shell ash sintered at $700{ }^{\circ} \mathrm{C}$ for $8 \mathrm{~h}$. 
Proc. of the International Conference on Advances in Bio-Informatics and Environmental Engineering - ICABEE 2016. Copyright (c) Institute of Research Engineers and Doctors. All rights reserved.

ISBN: 978-1-63248-100-9 doi: 10.15224/ 978-1-63248-100-9-20

All major peaks around $20^{\circ}$ and $32^{\circ}$ have shown the presence of quartz and calcite phases respectively. The formation of phase was confirmed based on the literature [xxx] The ash samples expect almond Shell have shown the presence of sodium silicate with other accompanying phases such as aluminum and magnesium in the silica network. The $\mathrm{NaOH}$ treated almond shell explains the presence of sodium silicate and sodium silicate hydrate peaks around $22^{\circ}$ and $24^{\circ}$ respectively.

From the SEM analysis, it was found that ash samples have its own shape and size arrangement. Fig. 3. showed the SEM images.

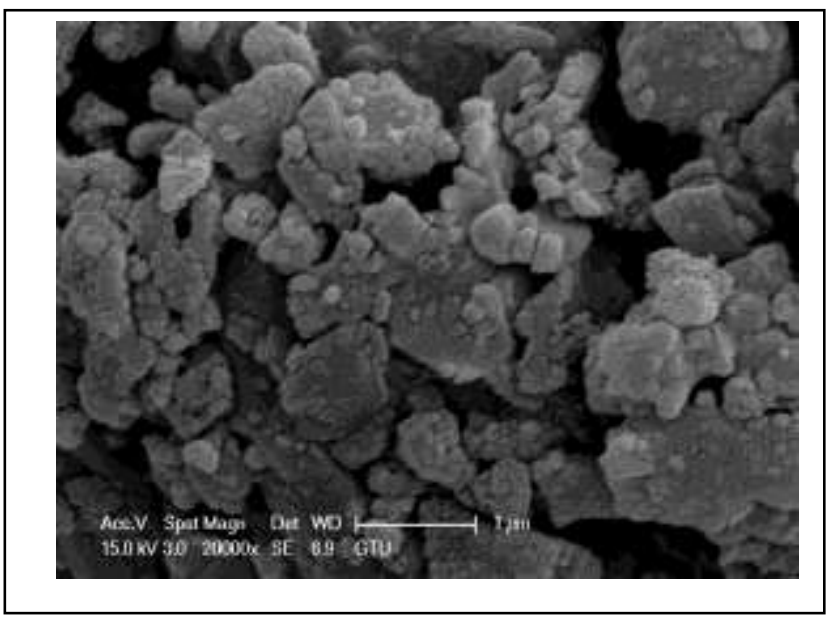

Figure 3. SEM images of almond shell ash

\section{Conclusion}

Silica was extracted from almond shell using alkali leaching and subsequent burning. The ash particles are subjected to sodium hydroxide treatment and showed the presence of sodium silicate with other accompanying phases such as $\mathrm{Al}, \mathrm{Na}$ and $\mathrm{Mg}$ in the silica network. After alkali extraction, silica contain ash was obtained with the yield of $52.20 \%$ (wt \%) from almond shell at $700{ }^{\circ} \mathrm{C}$ and $8 \mathrm{~h}$. Alkali leaching of the almond shell ash was carried out to remove soluble elemental impurities and hence it increases the purity of the silica content. All these results suggest that the ash obtained from waste materials would be a promising low cost raw material for the preparation of superfine silica.

\section{References}

[1] J. Emsley, Nature's Building Blocks AN A-Z Guide to the Elements. Oxford University Press, 2003.

[2] T.H. Liou, Preparation and characterization of nano-structed silica from rice husk, Materials Science Engineering A, 364, 2004, pp. 313 323.

[3] A. Chakraverty, P. Mishra, H.D. Banerjee, Investigation of combustion of raw and acid-leached rice husk for production of pure amorphous white silica,. Journal of Material Sciences, 23,1988, pp. 21-4.

[4] F. Ghorbani, H. Younesi, Z. Mehraban, M.S. Celik, A.A. Ghoreyshi, M. Anbia, Preparation and characterization of highly pure silica from sedge as agricultural waste and its utilization in the synthesis of mesoporous silica MCM-41, Journal of the Taiwan Institute of Chemical Engineers, 44, 2013, pp. 821-828.

[5] V. Vaibhav, U. Vijayalakshmi, M. Roopan, Agricultural waste as a source for the production of silica nanoparticles, Spektrochimica Acta Part A: Molecular and Biomolecular Spectroscopy, 139, 2015, pp. 515-520.

[6] P.K. Jal, M. Sudarshan, A. Saha, S. Patel, B.K Mishra, "Synthesis and characterization of nanosilica prepared by precipitation method" Colloid and Surface A: Physicochem. Eng. Aspects 240, 2004, pp. 173-178.

[7] V.B. Carmona, R.M. Oliveria, W.T.L. Silva, L.H.C. Mattoso, J.M. Marcncini, Nanosilica from rice husk: Extraction and characterization, Industrial Crops and Products, 43, 2013, pp. 291-296.

[8] S. Singh, L.C. Ram, R.E. Masto, S.K. Verma, A comparative evaluation of minerals and trace elements in the ashes from lignite, coal refuse, and biomass fired power plants International Journal of Coal Geology, 87, 2011, pp. 112-120 